\title{
Crisis Management: Lessons Learnt from the BP Deepwater Horizon Spill Oil
}

\author{
Mohamed MEJRI (Corresponding author) \\ 21 Quai de la Citadelle, B.P. 35528, 59383 Dunkerque Cedex 1, France \\ E-mail: mohamed.mejri@univ-littoral.fr
}

\author{
Daniel DE WOLF \\ University of Littoral Côte d'Opale
}

189 Boulevard Maurice Schumman, BP 5526, 59379 Dunkerque Cedex 1, France

E-mail: daniel.dewolf@univ-littoral.fr

Received: May 22, 2013 Accepted: May 30, 2013 Published: December 25, 2013

doi:10.5296/bms.v4i2.4950 URL: http://dx.doi.org/10.5296/bms.v4i2.4950

\begin{abstract}
The present paper studies the BP crisis management of the Deepwater Horizon Disaster which occurred on April 20 ${ }^{\text {th }}, 2010$. The authors content-analysed a large amount of secondary data from various sources, used the three-phase crisis management model and found that BP management of this crisis failed at many levels. The authors mainly highlighted four lessons relating to the connection between the Corporate Social Responsibility and the crisis management, the importance of the initial response when a crisis occurs, the need for strong stakeholders' relationship before, during and after the crisis; and the opportunity to learn from a crisis.
\end{abstract}

Keywords: Crisis management, British petroleum, Deepwater horizon, Stakeholders, Corporate social responsibility 


\section{Introduction}

On the 20th of April 2010, an explosion and a huge fire were declared in the oil rig Deepwater Horizon. This accident was considered as the largest maritime disaster oil spill in the US history because, aside from the death of eleven crews, its economic and environmental impacts were considerable.

Furthermore, the BP financial damages caused by this accident were particularly considerable. In the London Stock Exchange, the company shares loosed on June 25, 2010 nearly 7\% and fell to its lowest level since 14 years, while $50 \%$ of the its market capitalization was lost on early July 2010.

The company's reputation has also dramatically collapsed particularly in the U.S.A. Before the completion of sealing of the oil well, as the spill has progressed without a resolution, BP was awarded the grade the lowest grade $\mathrm{E}$, in the Covalence multinationals reputation ranking. The PRWeek/OnePoll's survey conducted about one month after the accident showed that the public feels that BP has not done enough to stop the leak. One year after the Deepwater Horizon oil spill, the "12th Annual Harris Interactive U.S. Reputation Quotient (RQ) Survey" revealed that BP was second from last with a score of 49.82 and that BP was still perceived by Americans as one of the companies with the worst corporate reputation (Harris Interactive, 2011).

BP was also facing, by mid-June 2010, remarkable calls for boycott of its products by a Facebook group called "Boycott BP" and numbering about 640,000 fans. Also, a fake BP Twitter account called @BPGlobalPR was made by an anonymous activist and started sending out messages about the Gulf oil spill to Twitter. By the end of May 2010, @BPGlobalPR had 190,035 followers while the BP account (@BP_America) had only 18, 826 followers. At last, BP was facing thousands claims and lawsuits from many actors such as fishers, hotels, restaurants as well as NGOs like the Animal Welfare Institute (AWI) and other animal protection and conservation organizations.

To deal with the spill oil as well as the reputation and financial losses, BP mobilized substantial means and expended a great deal of effort, but crisis experts' opinions differed on whether BP has successfully or unsuccessfully managed this crisis. However, many models and theories associated with crisis management can be used as a sound theoretical framework to assess BP crisis management of the Deepwater Horizon disaster.

Referring to the three-phase model, the most widely used model in the crisis management field, the purpose of this paper is to examine how BP managed the Deepwater Horizon spill oil. Such an investigation will help us to evaluate BP crisis management of this disaster, but will also give an empirical evidence to some ideas and propositions suggested by many crisis management researchers, not yet empirically validated or validated only through laboratory experiments. 
The reminder of the paper is organized as follows: the first section reviews the crisis management literature and focuses on the three-stage model. The second section describes the adopted methodology. The third and final section is dedicated to discuss the main lessons highlighted by this case study.

\section{Literature Review}

Because we are living in an "era of crises" (Lerbinger 1997), understanding and dealing with crises is becoming today, for both business practitioners and researchers, a real challenge.

Crisis management is a recent field of research and practice and is nowadays a continuously growing field of research.

While at the beginning, the weakness was the lack of theoretical development, it's today noteworthy, with the proliferation of research in this field that many developed ideas and theories remain purely theoretical and there is then a lack of empirical evidence of some theories.

In the following sub-sections, we tried to define and classify crisis, then we presented the crisis management model, but we mainly focused on the three phases' model as the most widely used framework in this research field.

\subsection{Crisis Definitions and Typologies}

A crisis was defined by so many authors but, as yet, there is no common and shared definition. Some definitions focus on the effects of a crisis on the organization. For example, Coombs (1999) defined a crisis simply as a situation that causes negative or undesirable outcomes for an organization. Lerbinger (1997: 4) viewed the crisis as "an event that brings, or has the potential for bringing, an organization into disrepute and imperils its future profitability, growth, and possibly its very survival". At last, Millar (2004: 19) viewed crisis as an event that "suddenly occurs, demands quick reaction, interferes with organizational performance, creates uncertainty and stress, threatens the reputation, assets of the organization, escalates in intensity, causes outsiders to scrutinize the organization, and permanently alters the organization".

Others point out that a crisis damages not only on the organization but also the whole system. Fearn-Banks (1996:1) regarded crisis as "a major occurrence with a potentially negative outcome affecting an organization, company, or industry, as well as its publics, products, services, or good name", while Pauchant and Mitroff (1992:15) considered that a crisis is "a disruption that physically affects a system as a whole and threatens its basic assumptions, its subjective sense of self, its existential core”.

At last, some definitions highlighted others aspects of a crisis, such as unpredictability, ambiguity, remedies, etc... For instance, Pearson and Clair (1998:60) perceived a crisis as "a low-probability, high-impact event that threatens the viability of the organization and is 
characterized by ambiguity of cause, effect, and means of resolution, as well as by a belief that decisions must be made swiftly".

On the basis of these different definitions, we can define crisis as an unpredictable event, whose causes, impacts and remedies are, at least at the beginning, ambiguous and that can potentially threatens the organization, its stakeholders, the industry as well as the whole eco-system.

To facilitate improvements in how companies manage a crisis, many scholars have made diverse attempts to classify crisis (Mitroff and Killman, 1984; Meyers, 1988; Lerbinger, 1997;Coombs, 1999 ; Coombs and Holladay, 2002). For example, Mitroff and Killman (1984) have identified seven types that they called corporate "evils": product tampering, product defects, product piracy, false accusation, danger of "groupthink" (insular thinking), hoaxes, and cultural insensitivity. Meyers (1988) identified nine types of business crises named crisis in public perception, sudden market shifts, product failures, top management succession, finances (cash drain), industrial relations, hostile takeovers, adverse international events and regulation and deregulation of the industry. Lerbinger (1997) developed four classes of crisis called technological crises, confrontational crises, crises of malevolence, and crises of managerial failure.

However, one of the most interesting and useful typology was first suggested by Coombs (1999) and recently refined and expanded by Coombs and Holladay (2002). These typologies were developed on the basis of the attributions of crisis responsibilities or the degree to which the organization is perceived to be responsible for the crisis. In fact, the authors consider that increased attributions of crisis responsibility generate stronger feelings of anger and low reputational scores and that "by identifying the crisis type, the crisis manager can anticipate how much responsibility stakeholders will attribute to the organization at the onset of the crisis thereby establishing the initial crisis responsibility level" (Coombs, 2007a : 166, 168).

Coombs (1999) classifies crises into nine basic categories named natural disasters, malevolence, technical breakdowns, human breakdowns, challenges, mega-damage, organizational misdeeds, workplace violence, and rumours. On the basis of the organizational responsibility, Coombs (2009) grouped these nine crises into five clusters (rumours, natural, disasters, malevolence, accidents and misdeeds).

Noting the important variations in crisis, Coombs and Holladay (2002) suggested a more refined typology of crisis situations and a repertoire of ten crisis-response strategies. The association between the crisis and the response taxonomies led to a new theory called the Situational Crisis Communication Theory (SCCT). The authors classified crisis into thirteen crisis types and grouped them into three clusters. Each of the crisis type in a cluster shares a similar level of crisis responsibility with the others (Coombs and Holladay, 2002).

The victim cluster includes crisis types in which the organization is considered a victim of the crisis along with the stakeholders (Natural disaster, Rumour, Workplace violence, Product tampering). All of these crisis types produce minimal attributions of crisis responsibility. 
The accidental cluster includes all crises that represent unintentional actions by the organization since it did not intend to create the crises (Challenges, Technical-error accident, Technical-error product harm). The crises in this cluster produce moderate attributions of crisis responsibility

The preventable cluster consists of crises which involve either purposefully placing stakeholders at risk, or knowingly taking inappropriate actions, or human error that could have been avoided (Human-error accident, Human-error product harm, Organizational misdeed with no injuries, Organizational misdeed, management misconduct, Organizational misdeed with injuries ).These crisis types produce strong attributions of crisis responsibility, and thus, represent a severe reputational threat to an organization.

\subsection{Crisis Management Models}

Crisis management, which has seen a steady evolution over the last 20 years (Jaques, 2007), aims to help organizations to manage crises and to minimize its negative impacts.

Coombs (2007b) considers that crisis management is a critical function for an organization, because failure in managing a crisis can result in serious harm to the stakeholders, losses for an organization, or end its very existence.

To highlight its importance for companies, several scholars have presented crisis management as a strategic activity. For example, Fearn-Banks (1996:6) considers that crisis management is by definition "a process of strategic planning for a crisis or negative turning point, a process that removes some of the risk and uncertainty from the negative occurrence and thereby allows the organization to be in greater control of its own destiny". Burnett (1998) argued that crisis management should be viewed as strategic action designed to avoid or mitigate undesirable developments and to bring about a desirable resolution of the problems, but recognized that "unfortunately, crisis management represents a strategic issue that looms as one most difficult to resolve because of both the additional elements of time pressure, limited control, and high uncertainty".

Many scholars have made diverse attempts to classify corporate crisis responses. For example, Siomkos and Shrivastava (1993) identified four different company response strategies to a product liability crisis called denial, involuntary product recall, voluntary product recall and super effort. Dawar and Pillutia (2000) stated that firm responses to product-harm crises can be considered along a continuum from unambiguous stonewalling to unambiguous support. Between the two extremes of unambiguous support and stonewalling lie ambiguous responses, whereby some dimensions suggest support and others do not. Coombs (1998) developed a model of crisis-response strategy by grouping various strategies into seven categories and placing them on a defensive-accommodative continuum. The defensive responses seek to protect an organization, whereas accommodative the responses seek to address the victim's concerns. Arranged from defensive to accommodative, the seven categories are as follows: attack the accuser, denial, excuse, justification, ingratiation, corrective action, full apology and mortification. 
Several authors viewed crisis management as a long-term process and suggested various stages models. All these models generally consider that managing a crisis can be analysed along a time continuum that extends from preventing and preparing crisis to recovering from crisis. These models represent then different approach to manage crisis and differ in term of stages number. Crisis management was then divided into three stages (Smith, 1990

Richardson, 1994; Hale et al., 2005; Coombs, 2007b), four stages (Myers, 1993, Jaques, 2007), five-stage framework (Pearson and Mitroff, 1993; Fink, 1986), six stages (Augustine, 1995) and even eight stages (the Home Office (UK) Emergency Planning College, cited by Harrison 1999).

Smith (1990), Richardson (1994) and Coombs (2007b) divided crisis management into three main stages. For example, Smith (1990) offered a three-stage format consisting of "the crisis of management" as a pre-crisis period; "the operational crisis" as a crisis period, and "the crisis of legitimation" as a post-crisis stage. Richardson (1994) offered a three-step framework similar to Smith's model. The pre-crisis/disaster phase focuses on prevention by addressing the threats that can cause a crisis. The crisis impact/rescue stage is the occurrence of the actual crisis. The recovery/demise stage involves restoring stakeholder confidence in the organization. Coombs (2007b) divided crisis management into three main work categories: First, pre-crisis stage which is concerned with prevention/preparation and aims to know what can be said or done to reduce the chance of crisis and moderate its harm if it occurs; second, the crisis stage as the actual response to a crisis; and third, the post-crisis stage concerned with the revision, the follow-up information, the lessons learned, and the preparation for next crisis.

Myers (1993) offered a four stage approach for managing a crisis that begins with the normal operations stage, a time when prevention practices are established. In this stage, operations are normal, but preparations are made to address an event that should occur. The second stage, emergency response, involves the first hours immediately following the onset of the crisis. Interim processing, the third stage, represents an intermediate phase where temporary procedures are set up until normal operations can resume. Restoration, the final stage, focuses on the transition back to normal operations.

Jaques (2007) also proposed a four-stage, relational but non-linear model to manage a crisis, and considers issue and crisis management in the context of interdependent activities and clusters of activity which must be managed at different stages. The four stages are respectively crisis preparedness, crisis prevention, crisis incident management and post-crisis management.

Pearson and Mitroff (1993) divided crisis management into the five phases namely signal detection, preparation and prevention, containment and damage limitation, recovery, and learning. Earlier, Fink (1986) subdivided crisis prevention stage into three stages (mitigation, planning, and warning), and suggested a five-stage model consisting of crisis mitigation, planning, warning, response, and recovery. 
Augustine (1995) suggested a six-stage model for crisis management. The suggested stages are avoiding the crisis, preparing to management the crisis, recognizing the crisis, containing the crisis, resolving the crisis, and profiting from the crisis.

The Home Office (UK) Emergency Planning College proposed an eight-stage planning process namely direction, information gathering, plan writing, consultation, publication, training validation, confirmation/revision (Harrison 1999).

Let's note that the three-stage model is the most known and used framework and that, as illustrated above in the models descriptions some scholars that have developed more stages model have only divided one or more stages into two or more stages. For example, compared to the three phase model, Fink (1986) has subdivided crisis prevention stage into three stages (mitigation, planning, and warning), Jaques (2007) divided the pre-crisis stage into two separate stages namely crisis preparedness and crisis prevention, while Pearson and Mitroff's model (1993) divided each of pre-crisis and post-crisis stages into two separate stages.

Then, regardless the model adopted, analysing the way and the performance of the organization in managing a crisis consists on seeing what it make before crisis occurs and how it responds to the crisis.

\subsection{The Three-Phase Model}

The three stages model is today the most widely used and recommended framework to analyse and manage crises. This model supposes that crisis management can be divided into three distinct phases, but the process should be viewed as holistic and integrated and its phases should be considered in aggregate rather than as separate sets of activities (Penrose, 2000).

The first phase, often labelled "pre-crisis phase" focuses on prevention and preparation. The second phase generally called "crisis response phase" begin when the crisis occurs and the management responds to it. The last phase, called "post-crisis phase" is a recovery phase that addresses the strengths and weaknesses of how the crisis was handled and allows the organization to better prepare for and prevent the next crisis.

In the following, we try to describe what should be done in the three phases; we mainly refer to the guideline suggested by Coombs (2007b) for managing a crisis.

\subsubsection{Pre-Crisis Phase}

In this stage, crisis manager should give an answer to the following question: what can be done or said to reduce the occurrence of the crisis and to minimize its possible damages if it occurs.

The pre-crisis phase is concerned with prevention and preparation (Coombs, 2007b).

Prevention involves seeking to reduce known risks that could lead to a crisis, such as implementing risk audits, safety measures and standards, a control system, scoreboards...

Coombs (2007b) recalls that no organization is immune from a crisis so all must do their best to prepare for one. Preparation involves creating the crisis management plan that should be 
updated annually, selecting and training the crisis management team, and conducting exercises to test the crisis management plan and crisis management team, and pre-draft some crisis messages. These crisis messages should include statements by top management, news releases and dark Web sites, which are separate communication channels designed for crisis situations.

Coombs also consider that spokesperson(s) training is a key component of crisis team training, because it (they) should be prepared to talk to the news media during a crisis. The author also argued that public relations can play a critical role in this field.

Many authors such as Hale et al. (2005) have highlighted the importance of building up, in this pre-crisis stage an image of legitimacy and trustworthiness because this serve the organization during the response phase. Heath (1997) called to implement "standards of corporate responsibility" to meet key publics' expectations" and Klein and Dawar (2004) argued that CSR acted as a company insurance policy in a crisis.

Coombs (2007) also argued that a negative history of crisis or negative prior relationships with stakeholders intensify attributions of crisis responsibility, and have both a direct and indirect effect on the reputational threat posed by the crisis. The author then concluded that crisis history and prior relationship reputation allow managers to anticipate how stakeholders will perceive and react to the crisis and the organization in crisis.

\subsubsection{The Response Phase}

The crisis response phase begins after the crisis occurs and involves management attempts to respond to a crisis. Some authors (e.g. Hale et al., 2005) consider this stage as the most critical of the three stages identified in crisis research literature.

During this period, management should work at mitigating the crisis and offering support to those affected by it (Richardson, 1994). Actions at this point significantly influence public opinion about the crisis and an organizations handling of the event (Hale et al., 2005).

Coombs (2007a) stated that, the first priority in any crisis should be to protect stakeholders from harms. Companies need then to be more open with sincere information to their stakeholders in order to help them cope with the psychological uncertainty from the crisis.

Coombs (2007b) also noted that public relations play a critical role in the crisis response by helping to develop the messages that are sent to various publics. The author called to separate the response phase in two sections: the initial crisis response and reputation repair and behavioural intentions

In the initial response crisis managers should be, quick- by delivering a response in the first hour after the crisis hits, accurate- because people want accurate information about what happened and how that event might affect them and consistent -by keeping spokespersons informed of crisis events and key message points and by working to have a consistent message between them. 
Coombs (2007b) also noted that organizations should firstly care about victims and seek way to help them instead of addressing their own concerns, because expressing concern/sympathy for victims can help to lessen reputational damage and to reduce financial losses.

Coombs (2007b) suggested a master list of Reputational Repair Strategies - which contains nine strategies and stated that they can be used in the crisis response phase, post-crisis phase, or both. The author adds that this list by itself has little utility and that crisis managers must rather know when a specific reputation repair strategy or combination of strategies should be used. Crisis managers must then follow a two-step process to assess the reputational threat of a crisis. The first step is to determine the basic crisis type while the second step is to review the intensifying factors of crisis history and prior reputation.

\subsubsection{The Post-Crisis Phase}

According to Coombs (2007b), the post-crisis phase begin when the organization return to business as usual and looks for ways to better prepare for the next crisis and fulfils commitments made during the crisis phase including follow-up information. The tri-part view of crisis management serves as the organizing framework for this entry. The author also noted that reputation repair may be continued on initiated during this phase.

Hale et al. (2005) consider that recovery involves attempts to learn from the event internally and handle the event externally.

Coombs (2007b) suggested three best practices to manage the post-crisis phase. First, organization must deliver all information promised to stakeholders as soon as the information is known. Second, organization must keep stakeholders updated on the progress of recovery efforts including corrective measures and investigations. Third, "organization should analyse the crisis management for lessons learned and to integrate those lessons into the organization's crisis management system" (Coombs, 2007b).

This last suggestion is very important for organization. Crises are in fact a perfect learning experience, and a real chance for changing the organization (Elliott et al., 2000).

Organizations should, then, evaluate what it has been doing prior to the crisis (including what led to the crisis and the crisis management effort). The post-crisis phase represents also an opportunity to preparing and preventing next possible crisis. Jaques (2007) stated that the end of every crisis should be the beginning of the preparation step for the next one. Penrose (2000) argued that companies which do survive disasters are more prepared for future challenges.

\section{Method}

To assess how BP managed the Deepwater Horizon disaster, we collected secondary data from various trustworthy sources, mainly newspapers, magazines, crisis experts' blogs and BP sustainability annual reports.

The collected data was analysed through Content Analysis by means of a grid drawn from our theoretical framework. The grid was compartmentalized mainly into three categories. The 
first one relates to the pre-crisis phase and was divided into three sub-categories named BP CSR and crisis history, BP crisis prevention and BP preparation to the crisis. The second category relates to the response and reputation repair and behavioural intentions. The third category relates to the post-crisis phase and lists all actions made by BP after the complete killing of the well.

\section{Results}

The results of our case study will take the form of a record of all actions made by BP before, during and after the disaster.

\subsection{BP Management of the Pre-Crisis Phase}

\subsubsection{The BP CSR and Crisis History}

Prior to the disaster, the social and environmental image of BP was paradoxical. The company was sometimes perceived as an environmentally committed company and sometimes as a polluting and irresponsible company. For several years, the group has specifically tried to differentiate itself from its competitors by displaying a greater environmental awareness. From 2000, the group adopted a new name (Beyond Petroleum instead of British Petroleum) and adopted a new green-white-and-yellow sunburst logo, spending more than $\$ 200$ million in an extensive advertising and public relations campaign.

Thanks to this, the BP brand awareness jumped from $4 \%$ to $67 \%$ between 2000 and 2007, the company image was considered as the most environmentally friendly image in comparison with companies operating in the oil sector (according to a 2007 customer survey), has been praised many times a model of proactive and credible corporate social responsibility and its advertising and public relations campaign won the Gold Award from the American Marketing Association.

BP has also positioned its self as a company fighting the climate change by promoting the renewable energy activities (including biofuels, hydrogen, solar and wind power), and was ranked as the leader in a 2006 report analysing the Climate Change Strategies of the top 100 global companies published by the Coalition for Environmentally Responsible Economies (CERES). BP was also among pioneer companies that begun to publish an annual sustainability and social responsibility report.

The BP CSR history has also a dark side. Indeed, the group was familiar with disasters and scandals and has a long history of safety negligence particularly in the United States (De Wolf and Mejri, 2013).

The Deepwater Horizon was not in fact the unique BP accident. The first known accident happened in December 1965 and caused the death of thirteen crew when the BP oil rig Sea Gem collapsed while it was being moved. On March 23, 2005, fifteen workers have been killed and more than 170 others have been injured when the BP's refinery exploded and caught fire in Texas City. The company was subject to lawsuits from the victims' families and 
was charged with criminal violations of federal environmental laws. One year later, an oil spill in Alaska caused extensive pipeline corrosion. The company also paid about $\$ 20$ million as environmental fines.

Furthermore, BP was many times cited as the worst or among the worst companies operating in USA because of some environmental and/or social impacts of its activities. BP was cited in 1991 by the Environmental Protection Agency (EPA) as the most polluting company in the US based on its toxic release data. It was also considered by CorpWatch as one of the ten worst corporations of 2000 (Mokhiber and Weissman, 2001). Mother Jones Magazine, an investigative journal, named BP as one of the ten worst corporations in both 2001 and 2005 based on its environmental and human rights records. In 2004, The Texas Public Interest Research Group reported that the company was number one in accidents in USA since 3,565 accidents occurred in its U.S. chemical plants and refineries between the period 1990 and 2004, making. Elder (2005) said that BP's operations have the worst safety records of any oil company operating in USA.

BP is also considered as one of the biggest spenders on lobbying among companies of the oil and gas industry. Also, BP was suspected to spent about \$625 million between 2004 and 2010 just to represent its interests in Washington and nearly \$16 million in 2009 to lobby to block attempts to regulate stricter safety by the US Congress.

\subsubsection{Crisis Prevention}

Succession of BP accidents demonstrates that the group was never concerned with prevention and safety. Almost all the investigations reports following the BP disasters revealed that the company had almost no prevention system and neglected security/safety warnings.

After the 2005 explosion at the BP's Texas City refinery, the Occupational Safety and Health Administration fined $\mathrm{BP}$ a record of $\$ 87$ million for neglecting to correct safety violations. Only a year later, BP was fined \$20 million in criminal penalties after prosecutors said the company had neglected corroding pipelines that caused the Alaskan BP oil spill.

The Congressional Investigations on energy and commerce following the Deepwater horizon Spill revealed that BP had no contingency plans for catastrophic loss of well control and that BP lacked planning, oversight, testing and maintenance of blowout preventer which failure allowed a large volume of gas to overwhelm the rig and caused the explosion. The preliminary BPs internal investigations realized one month after the Gulf oil spill also revealed that several warning signs of trouble were ignored and pointed to a series of equipment failures.

In addition, some experts and journalists claimed that BP made a series of money-saving shortcuts in days before the accident, which dramatically increased the danger of a blowout and that, worse still, the company neglected security standards on continuing to drill in spite of warnings of gas leak. 
It should be particularly noted that, while BP is considered and awarded as an environmental responsible company, the French social rating agency Vigeo reviewed, before the accident, the BP rating. The company was considered as the worst energy company in terms of preventing and controlling of pollution accident risks. On the basis of this criterion, Vigeo scored BP before the accident 26/100 (below the industry average which is equal to 31/100), while the leader Repsol collected a score of 61/100 (Ben Seddik, 2010).

At last, crisis management experts said that failures of BP prevention and control system was expected because of the budget cuts since the year 2009 (particularly the alternative energy budget) imposed by the former BP CEO, who also shut down BP alternative energy headquarters in London and accepted the resignation of its clean energy boss.

\subsubsection{Preparation to the Crisis}

It is clear that BP was not prepared to deal with such an accident. Besides, Former BP CEO Tony Hayward admitted in his interview to Money Programme on BBC 2 that "BP's contingency plans were inadequate", that BP "was not prepared" for the Gulf oil disaster and was "making it up day to day" in the early stages. Tony Hayward also admitted that "BP was not prepared to deal with the intense media scrutiny over the Gulf oil disaster" and that he felt he was "demonized and vilified". Nearly one month after the disaster, the Wall Street Journal reported that Hayward "admitted that the oil giant had not the technology available to stop the leak. He also said in hindsight, it was probably true that BP should have done more to prepare for such an emergency".

In addition, the investigations conducted by Congressional committee on energy and commerce concluded that BP was not prepared for a catastrophic loss of well control.

Nevertheless, BP has successfully established strong relations with some NGOs thanks to its considerable donations that reached prior the crisis nearly $\$ 10$ million in cash over the years. For example, the BP donations to the Conservation International which reached \$2 million over the years allowing to the company to be BP partner on a number of projects. Also, the Nature Conservancy listed BP as one of its business partners and even gave it a seat on its International Leadership Council but unfortunately after the Deepwater Horizon disaster, some of its members begun to questioning about this partnership and called to review it.

\subsection{BP Management of the Response Phase}

After the Deepwater Horizon blowout, BP has mobilized equipment and resources and has made significant efforts to stem the oil spill and to completely kill the well.

During five months, BP engineers tried a number of techniques to slow or to stop the oil leaking but all these attempts failed. BP engineers firstly attempted to close the blowout preventer valves on April 28. On May 8, they tried to cover the well with a containment box, and they tried the Top Kill technique on May 26 to close the well. They successfully stopped the flow of oil on July 15, and completely killed the well on September 19, 2010.

However, while the BP engineers were fighting for plugging the leaking well, BP managers 
were fighting for repairing the company reputation and the public perception that BP is not enough competent to manage this crisis. As recommended by Coombs (2007b), we separated this response phase into two phases: the initial response and the reputation repair and behavioural intentions.

\subsubsection{The Initial Response}

BP entirely failed to manage the initial response of the disaster and committed many flagrant mistakes. First, BP was accused of being slow to acknowledge the problem initially and of did not respond quickly enough. The company took four days to realise that the well itself was leaking. The company was also slow to express concern, compassion and full apology to victims which are most immediately affected by the spill.

Second, when the accident occurs, BP has intentionally underestimated the extent of the spill. The company estimated that only 1,000 barrels (159000 litres) were actually daily spewing into the Gulf, but quickly revised it upward to 5,000 barrels (795 000 litres). Actually, by the end of June, some scientists evaluated the daily oil leak at 60.000 barrels (9540000 litres).

Third, the BP former CEO Tony Hayward - as the company spokesman, made a series of mistakes while communicating about the crisis. Indeed, instead of expressing its compassion towards the victims, the former CEO initially took to lightly and even minimized its severity considering that "its environmental impact would likely be very very modest" and that it is "relatively tiny" in comparison with the big size of the ocean. He also told a news cameraman to "get out of there", complained that he wanted his life back stating to reporter that " there's no one who wants this thing over more than I do, I'd like my life back", and went to watch his yacht race while oil spews into the Gulf. As a consequence, Tony Hayward has become the most hated man in the United States and was replaced by Bob Dudley on October 2010.

Fourth, BP tried (by all the means) to limit or delay the flow of information to the public. The access to planes carrying media were refused and sometimes forbidden to many media reporters and the few reporters that were allowed to access, were accompanied by a BP representative. The company also included in workers contracts a clause prohibiting them and their deckhands from making news releases, marketing presentation or any other public statement.

Fifth, BP was suspected of covering up the oil by trucking in sand. The company denied the events and argued that "at no time has clean sand been used to cover or bury oil or oiled sand" and that "storms that have passed through the area have deposited sand on the beach and eroded it again exposing oil buried by sediments brought in by the weather".

Nevertheless, it is noteworthy that BP successfully used its official website (BP.com), to regularly provide information to the public about the clean-up efforts of the oil spill as well as the efforts to compensate victims of the disaster. 


\subsubsection{Reputation Repair and Behavioural Intentions}

In this phase, a company have normally to repair the reputation, to reduce negative affect and to prevent negative behavioural intentions.

To repair reputation damages, BP launched immediately after the accident, a vast public relations campaign. BP began running apologetic BP ads in early June, showing Hayward apologizing for the disaster and taking full responsibility for cleaning up the spill in the Gulf. The company also launched a print ads campaign in US newspapers like The New York Times, the Wall Street Journal, USA Today and The Washington Post. This ads campaign was widely criticized by many stakeholders and even by the President Barack OBAMA, who considered that the money should have been spent on clean-up efforts and on compensating victims.

BP was also very present in the major social networks (Facebook, Twitter, YouTube and Flicker) and spent nearly \$1 Million a month between Google AdWords and YouTube advertising and purchase a number of search terms in order to direct internet users' search queries about the Gulf oil spill to the BP site where clean-up efforts are exposed.

In order to reassure its primary stakeholders that it consider of high priority (shareholders, investors as well as other partners particularly in Russia and Azerbaijan), BPs former CEO flew to Mideast early July as the BP stock hit its lowest point since the mid-1990s and after the BP decision of selling assets. During these visits, the BPs former CEO held talks with sovereign wealth funds in Abu Dhabi, Kuwait and Qatar, as well as in Singapore, in order to find a partner who might help BP to avoid the threat of a hostile takeover offer from its closest competitors. As expected, these visits reassured many BP and generated some enthusiasm in the market for BP shares.

To remedy the loss of reputation due to the BP spokesperson failures, the company announced on July 27, that it would change its CEO Tony Hayward in October 2010, by the American CEO Robert Dudley. According to some experts, such a decision would certainly please a lot of Americans and contribute to repair the BP image.

Following a meeting with the President Barack OBAMA, BP announced that an agreement was reached to create a $\$ 20$ billion claims fund over the next three and a half years on the following basis: BP will initially make payments of \$3 billion in Q3 of 2010 and \$2 billion in Q4 of 2010. These will be followed by a payment of $\$ 1.25$ billion per quarter until a total of $\$ 20$ billion has been paid in (BP, 2010 b). In addition BP announced on August 17, that it would provide $\$ 52$ million to federal and state health organizations to fund behavioural health support and outreach programs across the US Gulf Coast region.

At last, BP "photoshopped" many photos and posted them on its Web site as news photos from the Gulf oil spill response effort. A few days later, being widely denounced and criticized by communication experts as well as the public opinion, BP officially acknowledged the facts and promised to stop this practice. 


\subsection{BP Management of the Post-Crisis Phase}

In the Deepwater Horizon case, the post-crisis phase began once the well was completely killed on September 19, 2010. However, due to the considerable damages caused by the accident, this recovery phase is expected to continue for several years. Ever since, many decisions and actions were made.

To cover the costs, BP decided to divest assets with a total value of $\$ 38$ billion between 2010 and the end of 2013. Until the end of March 2012, BP had sold \$ 23 billion of assets. Since early July 2010, BP has sold $\$ 7$ billion assets (in the Permian Basin, Canada and Egypt) to the firm Apache. In 2011, BP sold its Wytch Farm terminal fields to Perenco for \$610 million. On March 2012, BP agreed to sell for \$ 400 million to oil and gas company Perenco a number of platforms off the coast of Yorkshire and a terminal at Dimlington.

A few days before killing the well, BP published its own investigations report into the incident. BP claimed that its engineers, contractor Halliburton and rig operator Transocean share the blame for the "complex and interlinked series of mechanical failures, human judgments, engineering design, operational implementation and team interfaces" that caused the accident. Its former CEO said that there was a "lack of rigor and quality of oversight of contractors", that "a series of complex events, rather than a single mistake or failure" led to the accident and that it would be "surprising if the industry does not look afresh at the relationship with contractors". This BP internal report was widely criticized by experts who considered that it "does nothing more than spread the blame", as well as by BP partners Transocean and Halliburton. Transocean responded by describing the report as "self-serving" while Halliburton said that the BP report contained "substantial "errors.

On the other hand, BP has successfully convinced its three other partners on the well (Anadarko, Mitsui and Co. Ltd. and Weatherford International Ltd.) to settle its claims related to the Deepwater Horizon disaster. Anadarko agreed to pay BP \$4 billion (less than the $\$ 6.1$ billion that BP had claimed), Mitsui agreed to pay $\$ 1.06$ billion (less than the $\$ 2.14$ billion that BP had billed it for its alleged share of clean-up costs) and Weatherford International Ltd. announced that it would provide $\$ 75$ million to BP to contribute to the Gulf Coast recovery fund

BP also launched lawsuit against Halliburton, Transocean and Cameron and is seeking at least $\$ 40$ billion from them. BP considers that maintenance by Transocean was inadequate as was their safety and training protocols, that Halliburton was responsible for cementing or sealing off the well and that Cameron International Corp was responsible for designing and maintaining the blow-out preventer which failed to contain the oil spill.

Nearly one year after the accident, BP published its first sustainability report after the disaster. At the beginning, in the CEO letter, the Chairman Bob Dudley acknowledged that the company was sorry for what happened, promised improvements and stated that safety has become their number one priority. Besides, the chairman used nine times the word safe which demonstrates the importance of the issue safety for the new BP. 
However, the report does not say how the disaster happened and how much damage was actually done to the environment, the economy and the people. It mainly described how BP is changing. The company said it is forming a Safety and Operational Risk function that has its own expert staff embedded in BP's operating units (including exploration projects and refineries) report directly to the company's incoming chief executive officer and that has authority to intervene in all aspects of BP's technical activities.

As for the other changes, the company stated that it has reviewed its Risk management system, has reorganized its upstream business into three divisions - exploration, developments and production - with a centralization of the drilling wells activity into a single organization, has connected the individual values/behaviours and the BP code of conduct, has aligned employee performance and reward with the performance management system, has reviewed how it works with contractors and other industry partners, has repositioned the technology to meet the 2lst-century energy demand safely and responsibly and has lastly initiated a review into its approach to the management of relationships with significant non-operated joint venture operators and partners (BP, $2010 \mathrm{a}$ ).

This first post-Deepwater Horizon CSR report was considered by many experts as a purely greenwashing and was then widely criticized._In fact, BP said it couldn't include the Gulf spill, because there has been "no accurate determination" of its size and refused to list any figures from the accident. The company argued that "no accurate determination can be made or reported until further information is collected and the analysis, such as the condition of the blowout preventer, is completed" and that "We have not included any emissions from the Deepwater Horizon incident and the response effort due to our reluctance to report data that have such a high degree of uncertainty". In addition, the report showed that 2010 had the lowest spillage by comparing BP's oil spill levels for 2006, 2008, and 2010 (1.7 million litters in 2010, as opposed to 2.2 and 3.4 million in the earlier years).

As for supporting the communities affected by the disaster, BP accepted to settle lawsuits (for $\$ 7.8$ billion) brought against the company by businesses and individuals and to pay about to them. The estimated compensation includes provisions for $\$ 2.3$ billion to bolster the region's seafood industry and $\$ 105$ million to improve available health care in the impacted communities. BP also agreed to provide periodic medical consultations for the next 21 years for those with spill-related health complaints. Experts recalled that Exxon Mobil agreed to pay damages to settle the Alaska spill oil twenty years later and considered that this agreement is for BP a significant step to support the affected communities and to repair its reputation damages.

Most recently, BP began through workshops with its influential stakeholders around the world (in London, Washington DC, New Orleans and Rio de Janeiro), to initiate a dialogue to find out what they expect from BP's sustainability reporting. More than 40 stakeholders (including representatives of non-governmental organizations and community groups as well as academics, policymakers and investors) took part in these workshops which aimed to give BP a clear brief about what stakeholders want to know about its culture, plans, policies, 
processes and performance. The company already included a summary of the workshops findings in its 2011 sustainability report.

Lastly, BP has used a specialist market intelligence search engine to identify trends in public and stakeholder opinion about BP and to evaluate their potential to affect the company's reputation. A meta-analysis was also provided of all the recent stakeholder research and dialogue BP had carried out or commissioned.

\section{Discussion}

The analysis of BP crisis management of the Deepwater Horizon disaster shows mainly that there are many failures at managing the three phases of a crisis.

Through the analysis of BP environmental strategy before the crisis occurs, it turned out that it was just a Greenwashing, that safety was not a priority to BP, to the point that it has never envisaged an emergency plan, was not sufficiently prepared to such a catastrophic situation and did not make enough efforts to avoid crises. Worse still, only few days before the accident, BP neglected serious warnings and even cut corners on Deepwater Horizon safety.

When the crisis occurred, the BP initial response totally failed. The company was too slow, tried to blame third parties and abdicated responsibility while it would express concern for the victims and take its responsibility and reassure all the stakeholders. BP even aggravated its reputation damages when it censured or delayed the information flow and refused to cooperate with the media.

Even after the crisis, BP continues to conceal important information about the real damages of the spill oil, disseminated only information that can contribute to repair its reputation and continues to blame its partners. Besides, through the succession of accidents and scandals, it seems that BP has never believed that it could learn from such crisis.

In the light of this case study, at least four lessons can be learnt. The first lesson refers to the strong connection between CSR and crisis management. This BP case study is in fact a strong reminder that companies should nowadays sincerely embrace the principles of social and environmental responsibility and have to consider themselves responsible for more than bottom-line results. Crisis management literature showed that in time of crisis, CSR acted as a company insurance policy (Klein and Dawar, 2004) and that the company's history has an instrumental effect on how it will be perceived when a crisis occurs (Maresh and Williams, 2010). It is noteworthy that prior to the crisis, BP had tried to build up an image of legitimacy and trustworthiness, but this does not help it during the disaster. This is due mainly to the lack of credibility of its discourse. This consequently demonstrates the dangers of the greenwashing strategy and the propagandist discourse. Carrying a continuous speech of socially responsible company increases, apparently, stakeholders' expectations in times of crisis, and this in turn generates more pressures on it. 
In addition, we should not forget that CSR aims, among other things, to protect the interests of all the stakeholders. Preventing and being prepared for a crisis should then be viewed as part of the company social responsibility.

We believe that, if BP had set up a prevention and crisis management system and if BP and its former CEO were well prepared to manage such event, this crisis could have been avoided or would have been resolved sooner or at least damages would have been greatly reduced. Crises are in fact, often unpredictable, so it is important to establish a crisis prevention system to reduce the likelihood of, and anticipate the occurrence of a risk and acts as quickly and as efficiently as possible in case of occurrence of a crisis.

The second lesson relates to the importance of initial response when a crisis occurs.

In this phase, $\mathrm{BP}$ was neither quick, nor accurate and consistent. BP failed then to manage the initial response phase which caused to the company a remarkable reputation loss.

As many companies, BP seems to ignore that communication during the first hours of a crisis can have remarkable implications for the image of a company and a brand (Dawar and Pillutla, 2000), that almost $80 \%$ of a crisis management consists of communication and that much of a crisis lies not in its reality, but in its perception.

This case study, demonstrates that initial actions made by a company in times of crisis, significantly influence public opinion about the crisis and an organization's handling of the event (Hale et al, 2005).

More notably, as predicted by Ulman (2001), BP initial crisis communication was largely focused on legal concerns and resulted in denials of responsibility, minimization of the exent of damages and lack of useful information to stakeholders. Referring to Coombs (2007b), in the initial response phase, BP should have provided information and should have taken actions that might help affected people to cope psychologically and physically with the crisis. For BP it was better to take its responsibility, to reassure victims and specifically to begin by expressing concern for the victims of the crisis which could reduce the negativity effect of the crisis.

BP also ignored that when a crisis occurs, crisis leaders, specifically spokesperson have a central role in building and sustaining organization' $s$ trust and credibility among stakeholders (Schoenberg, 2005) and that in times of crisis, leaders and therefore spokesperson must be able to communicate with all stakeholders and should be exceptional communicators (Seijts, 2004). Because of being not prepared to a crisis, former BP CEO has significantly contributed to BP loss of reputation with his arrogance, negligence and famous statements.

This case study provides then empirical evidence on the importance of the initial actions in times of crisis as a significant factor influencing the public opinion about the crisis and an organization's handling of the event (Hale et al., 2005). 
The third lesson refers to the relationship between the company and its stakeholders. This case study is in fact a strong reminder that a company should no longer operate independently of their stakeholders. It has rather to interact and to build strong relationship with them, not only during and after a crisis, but also prior to a crisis.

Prior to crisis, the company can benefit from its interaction with its stakeholders by implementing standards of corporate responsibility that meet their expectations (Heath, 1997), by understanding how stakeholders might react to a crisis, what resources and information they might have available to assist in the management of a crisis, how they might be impacted by the crisis, and how they might exert a negative impact on the organization's ability to manage the crisis (Mitroff et al., 1996). In addition, companies that build alliances and achieve coordination with their stakeholders prior to a crisis will experience greater success outcomes and less failure outcomes in crisis management than will those organizations lacking such alliances (Pearson and Clair, 1998).

Even, if the interaction with stakeholders can not help an organization avert every crisis, it can at least play an important role in how the organization resolves a crisis (Ulmer, 2001). Otherwise, if a company doesn't have strong relationship with its stakeholders, they may withdraw their support during a crisis, prolong the effects of a crisis and even intensify the threat associated with the event (Ulmer and Sellnow, 2000).

Furthermore, during a crisis, companies have to be open and transparent vis-à-vis of their stakeholders instead of emphasizing their own concerns over those of them. They must rather cooperate with them, respond to their questions and keep them up-to-date on a company's crisis plans and actions.

In addition, Stakeholders want to feel informed, safe and connected when a crisis occurs (Seijts, 2004). So, open, timely and trustworthy reporting, as well as regular dialog and communication with all stakeholders should be maintained in times of crisis. The company should also be honest about what it knows and does not know, which would give it far more credibility. Specifically, the company must not ignore the central role of media during the crisis, because the majority of the information stakeholders collect about organizations is mainly derived from the news media; therefore media coverage is an important feature of reputation management (Carrol and McCombs, 2003). Seeger (2006: 240) said that "rather than viewing the media as a liability in a crisis situation, risk and crisis communicators should engage the media, through open and honest communication, and use the media as a strategic resource to aid in managing the crisis". Lastly, after a crisis, a company should collect information from a wide range of stakeholders -including external stakeholders and has to continue to work in close dialog with them in order to reduce feeling of anger and blame, to reassure them, to understand how they perceive and feel about it after the crisis and to involve them in effort to repair reputation damages (Coombs, 2010).

The fourth and last lesson is that company should learn from a crisis. The succession of BP accidents demonstrates that nothing has been learned from its previous accidents. From the 
beginning of the crisis and until today, BP often gets defensive position and denies its whole responsibility.

Ideally, companies should consider the end of every crisis as the beginning of the preparation step for the next one (Jaques, 2007). Recovery is not just getting back to work, but it is asking, what we have learned to prevent this happening again and what could we have done differently. Surely, crisis inevitably creates severe harm, but it also has the potential to serve as a renewing force for the organization (Seeger et al., 2005). Companies which can survive after disasters are more prepared for future challenges (Penrose, 2000). Unfortunately, this is often not the case.

At last, companies would not learn only from their own experiences, they must consider the critical events and experiences of other companies and try to learn from them (Baum and Dahlin, 2007). Besides, the BP disaster has served as a lesson to its closest competitors. Four of the world's largest oil companies (Exxon Mobil, Chevron, Shell and ConocoPhillips) agreed to form a \$1 Billion joint venture, called the Marine Well Containment Company, to create a rapid-response system to capture and contain oil spills in the deep waters of the Gulf of Mexico. The created new company aims to develop response plan and technology that will be able to act into 24 hours and to capture and contain up to 100,000 barrels of oil from deep-water rigs in the case of an accident.

\section{Conclusion}

This paper aims mainly to examine how BP managed the Deepwater Horizon spill oil, the worst environmental disaster the US has faced. It reveals that because of many failures as well as its negative history, BP was fighting two crises at the same time, the big spill oil and the deep loss of its reputation.

In spite of being purely exploratory, this case study enabled us to give some empirical evidence to some propositions - as yet theoretical, and to highlight lessons learned from the management of the disaster. It mainly reminds us; first that CSR and crisis management are connected concepts. Second, that in time of crisis, the initial response has major repercussions on company image and reputation. Third, that company should consider stakeholders as effective partners when managing a crisis, and fourth that crisis has the potential to serve as a renewing force for the organization. The organization should then learn from crisis to prevent next crises and to be prepared for them.

As for the research perspectives, we particularly and strongly recommend to deepen the examination of the effects of reputations repair strategies on the company reputation depending on a crisis type, because we think it can effectively help crisis managers to prevent, to prepare for and to deal with crisis. We can at this level inspire from the Coombs Situational Crisis Communication Theory (SCCT), which will contribute to give empirical evidence to its assumptions. 
At last, it should be noted that this case study is one of the few researches whose results are not derived from a laboratory experimental research. Nevertheless, adopting a qualitative approach using only secondary data and giving our own interpretations to some events, does not allow us to draw generalizations from the results of this study. Besides, that has never been our intention.

\section{References}

Augustine N. R. (1995). Managing the crisis you tried to prevent. Harvard Business Review, 73(6), 147-158.

Baum, J. A., \& Dahlin, K. B. (2007). Aspiration performance and railroads' patterns of learning from train wrecks and crashes. Organization Science, 18(3), 368-385. http://doi:10.1287/orsc.1060.0239.

BP (2010a). BP Sustainability Review $2010 . \quad$ [Online] Available: http://www.bp.com/assets/bp_internet/globalbp/STAGING/global_assets/e_s_assets/e_s_asse ts_2010/downloads_pdfs/bp_sustainability_review_2010.pdf.

BP (2010b). BP Establishes \$20 Billion Claims Fund for Deepwater Horizon Spill and Outlines Dividend Decisions. [Online] Available: http://www.bp.com/genericarticle.do?categoryId=2012968andcontentId=7062966

Burnett, J. J. (1999). A strategic approach to managing crises. Public relations review, 24(4), 475-488.

Carroll, C. E., \& McCombs, M. (2003). Agenda-setting effects of business news on the public's images and opinions about major corporations. Corporate Reputation Review, 6(1), 36-46.

Coalition for Environmentally Responsible Economies (2006). Climate-change-strategies Ranking of 100 Global Companies, Mars 2006. [Online] Available: http://www.ceres.org/press/press-releases/bp-receives-top-score-in-first-ever-ranking-of-100global-companies-on-climate-change-strategies.

Coombs, (2007b). Crisis Management and Communication. Institute for Public Relations. [Online] Available: http://www.instituteforpr.org/topics/crisis-management-and-communications/

Coombs, W. T. (1998). An analytic framework for crisis situations: Better responses from a better understanding of the situation. Journal of Public Relations Research, 10(3), 177-191.

Coombs, W. T. (1999). Ongoing crisis communication: Planning, managing and responding. Thousand Oaks, CA: Sage.

Coombs, W. T. (2007a). Protecting organization reputations during a crisis: The development and application of situational crisis communication theory. Corporate Reputation Review, 10(3), 163-176. 


\section{Macrothink}

Business Management and Strategy

ISSN 2157-6068

2013, Vol. 4, No. 2

Coombs, W. T. (2009). Conceptualizing crisis communication. Handbook of crisis and risk communication, 100-119.

Coombs, W. T. (2010). Parameters for crisis communication. The handbook of crisis communication, 17-53.

Coombs, W. T., \& Holladay, S. J. (2002). Helping Crisis Managers Protect Reputational Assets Initial Tests of the Situational Crisis Communication Theory. Management Communication Quarterly, 16(2), 165-186.

Dawar, N., \& Pillutla, M. M. (2000). Impact of product-harm crises on brand equity: The moderating role of consumer expectations. Journal of Marketing Research, 215-226.

De Wolf D., \& Mejri M. (2013). Crisis Communication failures: The BP case study. International Journal of Advances in Management and Economics, 2 (2), 48-56.

Elder, L. 2005. Group wants powerful acid out of BP's plant, The Daily News, March 27, 2005 .

[Online]

Available:

http://galvestondailynews.com/story.lasso?ewcd=da267531b07af737.

Elliott, D., Smith, D., \& McGuinness, M. (2000). Exploring the failure to learn: Crises and the barriers to learning. Review of Business, 21(3), 17.

Fearn-Banks, K. (2006). Crisis communications: A casebook approach. Routledge.

Fink, S. (1986). Crisis management: Planning for the inevitable. New York: American Management Association.

Hale, J. E., Dulek, R. E., \& Hale, D. P. (2005). Crisis Response Communication Challenges: Building Theory from Qualitative Data. Journal of Business Communications, 42 (2), 112-134.

Harris Interactive (2011). The 2011 Harris Interactive Annual RQ Summary Report: A survey of the U.S. General Public using the Reputation Quotient. [Online] Available: http://www.rankingthebrands.com/PDF/The\%20Reputations\%20of\%20the\%20Most\%20Visi ble\%20Companies\%202011,\%20Harris\%20Interactive.pdf

Harrison, S. (1999). Disasters and the media: managing crisis communications. Macmillan Press, 1999.

Heath, R. L. (1997). Strategic Issues Management: Organizations and Public Policy Challenges. Thousand Oaks, CA: Sage.

Jaques, T. (2007). Issue management and crisis management: An integrated, non-linear, relational construct. Public Relations Review, 33(2), 147-157.

Klein, J., \& Dawar, N. (2004). Corporate social responsibility and consumers' attributions and brand evaluations in a product-harm crisis. International Journal of research in Marketing, 21(3), 203-217. 
Lerbinger, O. (1997). The Crisis Manager: Facing Risk and Responsibility, Lawrence Elbaum Associates Publishers, New Jersey.

Maresh, M., \& Williams, D. E. (2010). Oil industry crisis communication. The Handbook of Crisis Communication, 285-300.

Meyers, G. C. (1988). Managing Crisis: A Positive Approach. Boston: Houghton Mifflin.

Miller, D. (2004). Exposing the errors: An examination of the nature of organizational crisis, in responding to crisis: A rhetorical approach to crisis communication.

Mitroff, I. I., \& Kilmann, R. H. (1984). Corporate tragedies: Product tampering, sabotage, and other catastrophes. New York: Praeger.

Mitroff, I. I., Pearson, C. M., \& Harrington, L. K. (1996). The essential guide to managing corporate crises: A step-by-step handbook for surviving major catastrophes. New York: Oxford University Press.

Mokhiber, R., \& Weissman, R. (2005). The 10 Worst Corporations of 2005. Multinationalmonitor.org. 14 Oct. 2005. [Online] Available: http://www.multinationalmonitor.org/mm2005/112005/mokhiber.html.

Myers, K. N. (1993). Total Contingency Planning for Diasters: Managing Risk... Minimizing Loss... Ensuring Business Continuity. John Wiley and Sons, Inc..

Pauchant, T. C., \& Mitroff, I. I. (1992). Transforming the crisis-prone organization: Preventing individual, organizational, and environmental tragedies. Jossey-Bass.

Pearson, C. M., \& Clair, J. A. (1998). Reframing crisis management. Academy of management review, 23(1), 59-76.

Pearson, C. M., \& Mitroff, I. I. (1993). From crisis prone to crisis prepared: A framework for crisis management. The academy of management executive, $7(1), 48-59$.

Penrose, J. M. (2000). The role of perception in crisis planning. Public Relations Review, 26(2), 155-171.

Richardson, B. (1994). Socio-technical disasters: profile and prevalence. Disaster Prevention and Management, 3(4), 41-69.

Schoenberg, A. (2005). Do crisis plans matter? A new perspective on leading during a crisis. Public Relations Quarterly, 50(1), 2-6.

Seeger, M. W. (2006). Best practices in crisis communication: An expert panel process. Journal of Applied Communication Research, 34(3), 232-244.

Seeger, M. W., Ulmer, R. R., Novak, J. M., \& Sellnow, T. (2005). Post-crisis discourse and organizational change, failure and renewal. Journal of Organizational Change Management, 18(1), 78-95. 
Seijts, G. H. (2004). Walking on water or sinking without a trace? Six behaviours that describe strong crisis leaders. Ivey Business Journal, 69 (2), 1-6.

Siomkos, G., \& Shrivastava, P. (1993). Responding to product liability crises. Long Range Planning, 26(5), 72-79.

Smith, D. (1990). Beyond contingency planning: Towards a model of crisis management. Organization and environment, 4(4), 263-275.

Ulmer, R. R. (2001). Effective crisis management through established stakeholder relationships Malden Mills as a case study. Management Communication Quarterly, 14(4), 590-615.

Ulmer, R. R., \& Sellnow, T. L. (2000). Consistent questions of ambiguity in organizational crisis communication: Jack in the Box as a case study. Journal of Business Ethics, 25(2), 143-155.

\section{Copyright Disclaimer}

Copyright reserved by the author(s).

This article is an open-access article distributed under the terms and conditions of the Creative Commons Attribution license (http://creativecommons.org/licenses/by/3.0/). 